\title{
STUDIUL BOTANIC AL UNOR SEMINTE CARBONIZATE DIN CÂTEVA AŞEZĂRI ARHEOLOGICE APARTINÂND EVULUI MEDIU
}

Marin Cârciumaru

Rodica Dincă

Materialul paleobotanic ne-a fost oferit de o serie de colegi arheologi de-a lungul unei perioade de mai mulţi ani. Tuturor le aducem mulţumirile noastre pentru încrederea care ne-au acordat-o.

Acest studiu cuprinde de fapt determinările propriu-zise ale materialului, fără a discuta contextul în care acestea au fost descoperite, eventual implicaţiile care ar rezulta. Am considerat că aceste aspecte este mai bine să fie fácute prin discuţiile directe cu fiecare arheolog care a efectuat săpăturile în aşezarea respectivă.

Cele câteva loturi de materiale, în măsura în care am beneficiat de date cronologice asupra fiecăruia, le-am descris în această ordine, de la cele mai vechi la cele mai recente.

IZVOARE (com. Gogoşari, jud. Giurgiu)

Seminţele provin în urma săpăturilor din anul 1967 Cu următoarele notaţii: M-146, sec. VIII. Matrialul respectiv ne-a fost oferit de regretatul arheolog Bucur Mitrea.

Mostra se prezintă sub forma unor fragmente rezultate probabil dintr-un bloc bine compactizat, mai cu seamă pe unele laturi. Materialul botanic este în general prost conservat ceea ce a fácut foarte greoaie determinarea sa. Semințele aparţin, în marea lor majoritate, speciei Panicum miliaceum. Pentru că separarea seminţelor a fost aproape imposibilă, orice încercare având ca rezultat distrugerea materialului, nu excludem ca în conţinutul probei să fi fost şi alte specii.

\section{ROŞIEȘTI}

Aşezarea arheologică se găsește în punctul "Stana Costeşti" sau "Podul Doamnei", satul Gara Roşieşti, jud. Vaslui.

Materialul, aparţinând sec. VIII - IX, provine din groapa nr. 1 săpată în 1977 şi ne-a fost oferit cu multă amabilitate de colectivul de cercetare format din Ghenuţă Coman şi Ruxandra Maxim Alaiba.

Ascezarea este situată în Pod. Bârladului, în cadrul Dealurilor Fălciului, mai exact în platoul Abeştilor (cca. 200 - $300 \mathrm{~m}$ altitudine). Staţiunea este aşezată pe un promontoriu de forma unui grind.

Materialul botanic care ne-a fost pus la dipoziţie cuiprinde două loturi:

- un prim lot cu seminţe carbonizate separat de arheologii care au făcut săpăturile,

- un al doilea lot de material, care a fost selectat de către noi.

Primul lot a constat din 1602 semințe aparţinând următoarelor specii:

Hordeum vulgare vulgare $=59,7 \%$

Dimensiuni (mm)

$\begin{array}{llll} & \text { maximă } & \text { medie } & \text { minimă } \\ \text { Lungime } & 9,0 & 8,0 & 5,1 \\ \text { Lăţime } & 3,5 & 3,0 & 2,0 \\ \text { Înălțime } & 2,9 & 2,3 & 1,6\end{array}$


Hodeum vulgare nudum $=5,9 \%$

Dimensiuni $(\mathrm{mm})$ maximă medie minimă

$\begin{array}{llll}\text { Lungime } & 7,2 & 6,0 & 5,5 \\ \text { Lrţime } & 3,3 & 2,8 & 2,5 \\ \text { Innălţime } & 2,5 & 2,0 & 1,7\end{array}$

Secale cereale $=33,3 \%$

Dimensiuni (mm) maximă medie minimă

$\begin{array}{llll}\text { Lungime } & 9,0 & 8,0 & 5,1 \\ \text { Lăţime } & 3,5 & 3,0 & 2,0 \\ \text { Înălţime } & 2,9 & 2,3 & 1,6\end{array}$

Avena sativa $=0,9 \%$

Din cel de-al doilea lot au fost determinate 72 de semințe și au fost recunoscute următoarele specii:

Setaria sp. = 54 seminte;

Sinapis sp. $=7$ seminţe

Linum usitatissimum - 1 sămânţă

Panicum capilare - 1 sămânţă

Juncus sp. - 1 sămânţă

Artemisia sp. - 1 sămânţă

De asemenea, au fost recunoscute resturi de spic de Hordeum sp și Secale cereale.

\section{FUNDU HERTII}

Cercetările arheologice, realizate de D. Teodor şi V. Spinei, în anul 1968 la Fundu Herţii (com. Cristineşti, jud. Botoşani), în punctul "La Redută", şanţ de apărare nr. 3, au permis recuperarea a trei eşantioane de semințe carbonizate repartizate în felul următor:

Proba nr. 1 - câteva sute de seminte carbonizate în agregate mici din care se detaşau cu uşurinţă semințe de Panicum miliaceum (în cea mai mare parte) și Panicum capilare.

Proba nr. 2 - materialul provine dintr-o groapă atribuită sec. IX sau $X$, din locuinţa 11 şi 18 săpate în 1970 şi 1973 şi constă din multă cenuşă, pământ ars, cărbune de lemn, ceva seminţe şi resturi de spice.

Speciile sunt identificate din cele 345 seminte cercetate:

Hordeum vulgare vulgare $=86,4 \%$

$\begin{array}{lllll}\text { Dimensiuni }(\mathrm{mm}) & & \text { maximă } & \text { medie } & \text { minimă } \\ & \text { Lungime } & 9,0 & 8,0 & 7,0 \\ & \text { Lăţime } & 4,0 & 3,2 & 2,8 \\ & \text { Înălţime } & 2,6 & 2,4 & 2,0\end{array}$


Seminţele de or apar adesea lipite, în forma iniţială din spic, ceea ce dovedește că, alături de resturile de spice, incendiul s-a produs înainte de treieratul recoltei.

Avena sativa $=2,6 \%$

Galium tricorne $=9 \%$

Dimensiuni (mm)

$\begin{array}{llll} & \text { maximă } & \text { medie } & \text { minimă } \\ \text { Lungime } & 3,0 & 2,2 & 1,9 \\ \text { Înălţime } & 1,9 & 1,4 & 1,3\end{array}$

Galium spurium $=2 \%$

Proba nr. 3 a fost constituită din 507, de la următoarele specii:

Secale cereale $=92,7 \%$

$\begin{array}{lllll}\text { Dimensiuni (mm) } & & \text { maximă } & \text { medie } & \text { minimă } \\ & \text { Lungime } & 8,0 & 6,8 & 4,3 \\ & \text { Lăţime } & 2,9 & 2,1 & 1,5 \\ & \text { Înălţime } & 2,2 & 2,1 & 1,7\end{array}$

Hordeum vulgare $=4,9 \%$

Triticum cf. aestivum $=1,8 \%$

Panicum miliaceum $=0,4 \%$

Polygonum sp. $=0,2 \%$

DINOGETIA (sat Garvân, com. Jijia, jud. Tulcea)

De la Dinogetja au fost studiate mai multe loturi de materiale, pe care le vom prezenta mai jos.

1. Dinogeţa - 1985 (15 VI), III, D, caroul C4, sec. X

Tribicum cf. dicoccum $=0,7 \%$

Triticum aestivum $=78,2 \%$

Dimensiuni $(\mathrm{mm})$ maximă medie minimă

$\begin{array}{llll}\text { Lungime } & 6,0 & 5,2 & 4,0 \\ \text { Lăţime } & 3,9 & 3,0 & 2,5 \\ \text { Înălţime } & 3,0 & 2,5 & 2,0\end{array}$

Triticum cf. compactum $=16,5 \%$

Dimensiuni (mm)

$\begin{array}{llll} & \text { maximă } & \text { medie } & \text { minimă } \\ \text { Lungime } & 4,7 & 4,1 & 3,5 \\ \text { Lăţime } & 3,7 & 3,2 & 2,5 \\ \text { Înălţime } & 2,2 & 2,2 & 2,0\end{array}$


Marin CÂRCTUMARU, Rodica DINCA

Triticum cf. durum $=2,1 \%$

Triticum sp. $=0,2 \%$

Hordeum vulgare $=0,2 \%$

Secale cereale $=2,1 \%$

2. Dinogeţia - 1985 (20 VIII), D, caroul C4, nivel bordei, sec. $X$

Proba conţine 208 seminţe.

Tribicum aestivum $=85,9 \%$

Triticum cf. aestivo-compactum $=3,3 \%$

Triticum cf. durum $=3,3 \%$

Triticum sp. $=0,9 \%$

Secale cereale $=6,1 \%$

3. Dinogeţia - 1985 (13 VIII), caroul C3, sec. $X$

S-au cercetat 45 de seminte care au fost atribuite speciilor

Triticum aestivum $=86,7 \%$

Triticum aestivo-compactum-13,3\%

4. Dinogetja 1985 (13 VIII), caroul b3, sec. $X$

Mostra constă din câteva grame de agregate de seminţe care s-au dovedit a aparţine speciei Panicum miliaceum.

5. Dinogeţa 1985 (30 VIII), D, caroul C4, groapă sub pietrar, sec. $X$

Această probă constă din cca. 40 - 50 grame de material constituit din seminţe de Panicum miliaceum.

6. Dinogetia 1984 (20 VIII), D, caroul b4, nivel feudal timpuriu

Au fost cercetate la microscop 165 de seminte, fiind atribuite următoarele specii:

Triticum dicoccum $=5,4 \%$

Triticum aestivum $=67,5 \%$

Triticum aestivum cf. spp. compactum $=6,6 \%$

Hordeum vulgare $=10,9 \%$

Secale cereale $=4,8 \%$

Vicia sp. $=4,2 \%$

Lens esculenta var. microspermae $=0,6 \%$ 
Studiul botanic al unor seminţe carbonizate din câteva aşezări anheologice aparţinând evulul mediu

\section{Dinogetia 1984, D, caroul b4}

Proba conţine un număr de 212 semințe, repartizate pe specii în felul următor:

Triticum aestivum $=6,1 \%$

Secale sereale $=29,2 \%$

Hordeum vulgare $=3,3 \%$

Avena sativa $=61,3 \%$

8. Dinogeţia 1984 (22 VIII), D, caroul b3, str. E-V, lângă D2

Această mostră conţine doar 4 seminţe de Triticum sp.

9. Dinogeţia, hambar la vest de intrarea în basilica romano-bizantină, lângă incintă, atribuite sec. XI - XII, nivelul incendiat.

Au fost studiate la microscop 1000 de seminţe aparţinând speciilor:

Hordeum vulgare vulgare $=98,3 \%$

Hordeun vulgare nudum $=0,9 \%$

Secale cereale $=0,1 \%$

Panicum miliaceum $=0,4 \%$

Galium spurium $=0,3 \%$

10. Dinogeţia, hambar la vest de intrarea în basilica romano-bizantină, lângă incintă, sec. XI - XII, nivelul incendiat.

Mostra constă dintr-un bloc compact de seminţe din care au rezultat câteva mii de seminte de Panicum miliaceum, între care se găseau amestecate 10 seminţe de Hordeum vulgare și 6 seminţe de Triticum aestivum.

\section{PĂCUIUL LUI SOARE}

Materialul ne-a fost pus la dispoziţie de arheologul Petre Diaconu şi provine dintr-o săpătură efectuată în 1981, în S. I A, 09 (-1,05 m), atribuit sec. XI.

Proba se prezintă sub forma unor agregate carbonizate şi într-o mică măsură din seminte desprinse din acestea, împreună conţinând câteva mii de exemplare care au fost atribuite într-o proporție covârşitoare speciei Panicum miliaceum, dar între care s-au găsit 2 seminţe aparţinând speciei Setaria italica.

\section{NUFĂRU (jud. Tulcea)} Adamesteanu.

Această mostră, atribuită sec. XI - XII, ne-a fost oferită de arheologul Mănucu

Mostra constă dintr-o cantitate destul de mare de semințe (probabil câteva mii), din care sau studiat la microscop doar 357 de seminte, atribuite speciei Lithospermum sp. Este curios faptul că semințele nu sunt carbonizate, dar par oarecum fosilizate şi sunt seci. Împreună cu ele s-au recuperat 
trei seminţe carbonizate de Panicum miliaceum şi o sămânţă de Triticum aestivum, de asemenea carbonizată. De aceea, noi considerăm că seminţele de Lithospermum sp. trebuiesc privite cu multă prudenţă.

A apărut, de asemenea, o sămânţă foarte curioasă, pe care nu am putut-o determina cărei specii îi aparține, dar care pare a fost perforată în scopul înşirării dintr-un colier.

Alte trei esantioane de seminţe de la Nufaru ne-au fost cedate de regretata arheolog Silvia Baraschi.

Prima dintre ele poartă următoare siglă - Nufăru 1979, S. I, necropolă, caroul 4, adâncimea $-0,48 \mathrm{~m}$, (lângă profilul dunărean). Au fost identificate speciile:

Triticum aestivum $=95,8 \%$

Triticum of. compactum =0,9\% (lungime $-5,0 \mathrm{~mm}$, lãţime $-2,1 \mathrm{~mm}$, înălţime $-2,7 \mathrm{~mm}$ ), Panicum miliaceumm-3,2\%, Vicia sp. - 0,1\%

Totalul seminţelor cercetate din acest eşantion a fost de 746 de seminţe.

A doua mostră este notată - Nufăru 1979, S. I, necropolă, caroul 4, adâncimea $-0,40$ m şi este constituită din câteva sute de seminţe diseminate amestecate cu cenuşă. Seminţele aparţin, în exclusivitate, speciei Panicum miliaceum.

În sfârşit, al treilea eşantion poatră notaţia - Nufăru 1979, S. I, necropolă, caroul 4, adâncimea $-0,60 \mathrm{~m}$, groapă.

Materialul este format din multe resturi de cărbune de lemn, un agregat de seminţe puternic carbonizate şi seminţe, de asemenea, carbonizate în stare liberă, ce par mai puţin carbonizate decât cele din agregat, cu toate că aparţin aceleiaşi specii de Triticum.

Lista completă a speciilor determinate rezultă dintr-o cantitate de 500 grame de material şi este următoarea (au fost observate sub lupa microscopului 788 de seminţe):

Triticum aestivum $=97,3 \%$

Dimensiuni $(\mathrm{mm})$ maximă medie minimă

$\begin{array}{llll}\text { Lungime } & 6,1 & 4,8 & 3,5 \\ \text { Lăţime } & 4,0 & 3,0 & 2,0 \\ \text { Înălţime } & 2,7 & 2,3 & 1,3\end{array}$

Panicum miliaceum = 2,3\% (Dimesiuni: lungime $-2,1 \mathrm{~mm}$, lățime $-1,9 \mathrm{~mm}$, înălţ̣me $-1,7 \mathrm{~mm}$ ) Carex rostrata $=0,3 \%$ (Dimensiuni: lungime $-2,8 \mathrm{~mm}$, lăţime $-1,5 \mathrm{~mm}$ )

Vicia sp. $=0,1 \%$

ORADEA "SAlCA" (jud. Bihor)

Materialul provine dintr-o săpătură de salvare condusă de regretatul arheolog N. Chidioşan în anul 1957 şi a fost atribuit sec. XII - XIII.

Semintele carbonizate au fost descoperite într-o groapă hambar, din interiorul unei locuinte de tip semibordei. Groapa a fost bine arsă în interior, Materialul se prezintă foarte curat, fiind format 
Studiul botanic al unor seminţe carbonizate din cåteva aşezări arheologice aparţinând evului mediu

în mare parte din serninţe întregi şi numai în mică măsură amestecat cu puţin cărbune şi pământ ars. Cenuşa aproape că lipsește.

Eşantionul cercetat la microscop conţine 545 de seminţe repartizate următoarelor specii:

Triticum aestivum $=85,5 \%$

Dimensiuni (mm) maximă medie minimă

$\begin{array}{llll}\text { Lungime } & 6,0 & 4,9 & 4,2 \\ \text { Lăţime } & 3,5 & 3,6 & 2,9 \\ \text { Înălţime } & 2,2 & 2,6 & 2,2\end{array}$

Secale cereale $=13,0 \%$

Dimensiuni (mm)

$\begin{array}{llll} & \text { maximă } & \text { medie } & \text { minimă } \\ \text { Lungime } & 6,9 & 5,4 & 4,6 \\ \text { Lăţime } & 2,2 & 1,9 & 2,5 \\ \text { Înălţime } & 2,0 & 1,8 & 1,0\end{array}$

Lolium temulentum $=0,6 \%$

Agrostemma githago $=0,7 \%$

Carexsp. $=0,2 \%$

ORASUL DE FLOCI (com. Giurgeni, jud. Ialomiţa)

Primul eşantion din această aşezare arheologică aparţine unui nivel de secol XV, rezultat din sectorul Avicola, S. LVII, caroul 2, locuinţa 3, adâncimea $-0,64$ m, săpat în anul 1985, seminţe din vas.

Cele 131 de seminţe provin de la specille Pisum sativum spp. arvense - 98,5\% şi Lens esculenta $-1,5 \%$.

Al doilea eşantion, provenit dintr-o săpătură din anul 1985, constând din seminte, în general, rău conservate, probabil din cauza unui incendiu foarte violent, a fost recuperat din sectorul Avicola, S. LVII, caroul 2, locuinţa 3, adâncimea $-0,64 \mathrm{~m}$, seminţe din ulcior.

Speciile identificate sunt următoarele: Triticum aestivum - 0,5\%, Triticum aestivocompactum - 23,8\%, Triticum compactum - 43,9\%, Triticum durum - 30,2\%, Hordeum vulgare $1,6 \%$.

TÎRGSSOR (jud. Dâmboviţa)

Materialul avut la dispoziţie a rezultat din săpăturile efectuate în anul 1975, caseta V B, groapa 6 (fundul gropii) atribuit sec. XV.

Au fost identificate speciile: 
Rubus caesius $=96,0 \%$

Dimensiuni (mm)

$\begin{array}{llll} & \text { maximă } & \text { medie } & \text { minima } \\ \text { Lungime } & 3,5 & 2,9 & 2,3 \\ \text { Lăţime } & 2,0 & 1,8 & 1,7 \\ \text { Înălţime } & 1,5 & 1,3 & 1,2\end{array}$

Artiplex cf. hastata $=3,3 \%$ (diametrul mediu $=3,3 \mathrm{~mm}$ )

Vitis vinifera $=0,14 \%$

Sambucus sp. $=0,09 \%$

Prunus institia $=0,38 \%$

Aceste procente rezultă din studiul a 2082 de seminte.

\section{VoIvozI (com. Popeşti, jud. Bihor)}

În urma săpăturilor din anul 1972, din S. III, caroul 3, de la adâncimea de $0,80 \mathrm{~m}$, dintr-un strat atribuit primei jumătaţi a sec. al XV-lea, s-au cercetat 1941 de seminte care au fost depozitate, probabil, într-o pivniţă.

Speciile recunoscute sunt:

Pisum sativum spp. arvense $=99,4 \%$

Dimensiuni (mm)

$\begin{array}{llll} & \text { maximă } & \text { medie } & \text { minima } \\ \text { Lungime } & 6,9 & 5,4 & 4,6 \\ \text { Lăţime } & 2,2 & 1,9 & 2,5 \\ \text { Înălţime } & 2,0 & 1,8 & 1,0\end{array}$

Camelina sativa $=0,3 \%$

Avena sativa $=0,7 \%$

Polygonum amphibium $=0,7 \%$

\section{DÎNGENI (jud. Botoşani)}

Săpăturile arheologice din anul 1977 în punctul "La Şanţ" (aproape de gara Dîngeni), pe terasa stângă a Jijiei, într-o groapă de provizii atribuită sec. XVII - XVIII, au oferit o mostră de seminţe destul de curioasă, formată din mai multe mii de exemplare necarbonizate şi nefosilizate de Panicum miliaceum, între care se amestecau 5 seminte de Setaria verticillata. De asemenea, au fost identificate 6 seminţe de Chenopodium hybridum, 26 seminţe de Chenopodium album şi o sămânţ̌a de Polygonum convolvulus.

\section{UDEȘTI (jud. Suceava)}

Pe podeaua unui bordei feudal, în urma săpăturilor din 1974, în secţiunea 5, caseta $A$, carourile $18-20$, s-a descoperit o coajă de prună provenind, probabil, de la Prunus domestica. 
Seminţele determinate şi prezentate în cadrul acestui studiu reprezintă un prim lot mare de astfel de materiale rezultate din săpăturile erheologice, care beneficiază de determinări sigure. Considerăm că ele constituie o contribuţie modestă la nţelegerea mai bună a economiei vegetale dintro serie de aşezări atribuite Evului Mediu din ţara noastră şi se exprimăm speranţa că cercetările arheologice viitoare vor scoate la iveală noi loturi de materiale care să beneficieze de determinări sigure în cadrul unor cercetări interdisciplinare cât mai complexe.

\section{The botanical stady of camenized seeds discovered in sevaral medieval archeological settlements}

Abstract

Abstract series of bothanical materials from Medieval settelements were studied and wetry to present the results as much as possible in a chronological succession. The following species were discovered for each settlement:

Izvoare - Panicum miliaceum; Roșieşti - Hordeum vulgare vulgare, Hodeum vulgare nudum, Secale cereale, Avena sativa, Setaria sp., Sinapis sp., Linum usitatissimum, Panicum capilare, Juncus sp., Artemisia sp.; Fundu Herţi - Panicum miliaceum, Panicum capilare, Hordeum vulgare vulgare, Avena sativa, Galium tricorne, Galium spurium, Secale cereale, Hordeum vulgare, Triticum of. aestivum, Panicum miliaceum, Polygonum sp.; Dinogeția - Triticum cf. dicoccum, Triticum aestivum, Triticum cf. compactum, Triticum cf. durum, Triticum sp., Hordeum vulgare, Secale cereale, Triticum cf. aestivo-compactum, Triticum aestivo-compactum, Panicum miliaceum, Triticum aestivum cf. Spp. compactum, Vicia sp., Lens esculenta var. microspermae,s Avena sativa, Hordeum vulgare vulgare, Hordeun vulgare nudum, Galium spurium, Hordeum vulgare Triticum aestivum, Păcuiul lui Soare Panicum miliaceum, Setaria italica, Nufărul - Lithospermu sp., Panicum miliaceum, Triticum aestivum, Triticum cf. compactum, Carex rostrata, Vicia sp.; Oradea "Salca" - Triticum aestivum, Secale cereale, Lolium temulentum, Agrostemma githago, Carex sp.; Oraşul de Floci - Pisum sativum ssp. arvense, Lens esculenta, Triticum aestivum, Tricucum aestivum-compactum, Triticum compactum, Tribicum durum, Hordeum vulgare, Târgşor - Rubus caesius, Artiplex cf. hastata, Vitis vinifera, Sambucus sp., Prunus institia, Voivozi - Pisum sativum spp., Camelia sativa, Avena sativa, Polygonum amphibium, Dîngeni - Panicum miliaceum, Setaria verticillata, Chenopodium hybridum, Chenopodium album, Polygonum convu/vulus, Udesti - Prunus domestica. 